\title{
Same-site multiple releases of translocated white rhinoceroses Ceratotherium simum may increase the risk of unwanted dispersal
}

\author{
Ole-Gunnar Støen, Mompoloki Lettie Pithagano and Stein R. Moe
}

\begin{abstract}
The Near Threatened white rhinoceros Ceratotherium simum went extinct in Botswana during the 20th century because of poaching. Several attempts have been made to reintroduce the species. From 2001 to 2003 four batches (a total of 32 individuals) of white rhinos were released in the Moremi Game Reserve. All were fitted with transmitters, ear notched and monitored on a regular basis. Rhinos released in the last batch moved significantly further from the release site compared to early batches. Six female rhinos from the last batch dispersed out of the Reserve. Activity area (95\% minimum convex polygon; MCP) sizes decreased with years after release and increasing density of rhinos but only density had an effect on the core area $(50 \%$ MCP) sizes. We conclude that the number of rhinos present in the area of release should be carefully considered before further individuals are released. When released in an area with rhinos that have established territories, the newly reintroduced individuals may be forced to disperse. If other areas of suitable habitat are available elsewhere in the same protected area, animals should be released at different sites to avoid unwanted long-term dispersal and to use the inverse density-dependent activity area sizes to maximize the rhino population in an area.
\end{abstract}

Keywords Activity area, Botswana, Ceratotherium simum, density dependence, dispersal, reintroduction, white rhinoceros

\section{Introduction}

R hinos have become flagship species for international R conservation (Emslie \& Brooks, 1999; Bowen-Jones \& Entwistle, 2002). To fulfil the high international demand for their valuable horns (Dublin \& Wilson, 1998; Emslie \& Brooks, 1999; Department of Wildlife and National Parks, 2005) hunting has driven both African species, the white rhinoceros Ceratotherium simum and black rhinoceros Diceros bicornis, to near extinction in several countries.

Ole-Gunnar Støen, Mompoloki Lettie Pitlagano* and Stein R. Moe (Corresponding author) Department of Ecology and Natural Resource Management, Norwegian University of Life Sciences, P.O. Box 5003, NO1432 Ås, Norway. E-mail stein.moe@umb.no

${ }^{*}$ Current address: Department of Wildlife and National Parks, Serowe, Botswana.

Received 30 June 2008. Revision requested 18 August 2008.

Accepted 11 March 2009.
Some of these countries have reintroduced rhinos (Hitchins et al., 1972; Hofmeyr et al., 1975; Booth \& Coetzee, 1988; Adcock et al., 1998; Linklater et al., 2006; Linklater \& Swaisgood, 2008). The aims have been to rebuild populations, preserve their long-term genetic diversity and provide buffers against future potential poaching (Brett, 1990; Adcock et al., 1998).

In Botswana both the white and the black rhino were extirpated during the 2oth century (Emslie \& Brooks, 1999; Department of Wildlife and National Parks, 2005). The white rhino was reintroduced in 1967 but almost extirpated by poaching for the second time by the end of the $1980 \mathrm{~s}$ (Tjibae, 2002; Department of Wildlife and National Parks, 2005). The few surviving white rhinos were captured in the beginning of the 1990 s and translocated to protected sanctuaries for safety and for breeding to build viable populations before the animals were returned to protected areas (Tjibae, 2002). Thirty-two white rhinos were reintroduced to the Mombo area of Moremi Game Reserve in 2001-2003. Globally, C. simum is categorized as Near Threatened on the IUCN Red List (IUCN, 2008).

Although translocations have been a key component of successful rhino conservation in Africa the management of these populations poses a challenge to wildlife managers (Brett, 1990). The first months after release in a new area has commonly been critical for introduced black rhinos, with mortality normally highest in this period (Brett, 1998; Linklater \& Swaisgood, 2008). A variety of factors play a role in the survival and breeding of the newly translocated animals, and young black rhino males do not adapt as quickly to their new environment as adult males and females (Brett, 1998; Linklater \& Swaisgood, 2008). Another factor in the success of reintroductions is whether animals remain where they are released (Rogers, 1988; Mosillo et al., 1999; Reinert \& Rupert, 1999; Stamps \& Swaisgood, 2007). In this study we test how same site multiple releases influence movements and activity area sizes of white rhinos after reintroduction to Moremi Game Reserve, Botswana, and how these parameters are influenced by sex, age, release batch, time elapsed after release and rhino density.

\section{Study area}

The study was conducted in the $4,871-\mathrm{km}^{2}$ Moremi Game Reserve (henceforth termed Moremi) in the eastern Okavango Delta in north-west Botswana (Dangerfield \& Schuurman, 
2000; Beehner et al., 2005). The reserve is generally flat and comprises flood plains with a network of waterways, lagoons and pans, islands and reed banks (Beehner et al., 2005). The vegetation gradually changes from dense mopane woodlands and riverine forests to open grasslands on the flood plains and aquatic vegetation in wetter areas. The vegetation is influenced by seasonal rainfall and periodic inundation by flood water, which is normally highest in August. Moremi has a well-defined summer wet season (November-April), a cool dry winter (May-August) and a hot dry period (September-October), with a mean annual rainfall of $475 \mathrm{~mm}$ (Dangerfield \& Schuurman, 2000).

\section{Methods}

As part of the joint Department of Wildlife and National Parks and Okavango Wilderness Safaris rhino reintroduction project, 32 white rhinos were translocated to Moremi during 2001-2003 (Table 1) and released in four batches. On arrival all rhinos were fitted with radio transmitters and marked with a unique pattern of ear notches, and released from the same boma. The animals were regularly tracked by vehicle or aircraft and positions recorded using a global positioning system. Age was known from previous owners or estimated based on Hillman-Smith et al. (1986).

For analysis, the animals were grouped by time of release into four batches (Table 1). The distance from the release site to 2,948 locations of 27 reintroduced rhinos (five died shortly after release and were not included in analyses) during 2001-2006 were calculated. Because they would not be expected to establish home ranges soon after release we use the expression activity area to describe the area used, which includes exploratory movements and dispersal events. Using the software RANGES 6 (Kenward et al., 2003) we calculated a $95 \%$ minimum convex polygon (MCP) to define these annual activity areas and a 50\% MCP to define the core activity areas for each individual. The use of $\mathrm{MCP}$, a common metric, facilitates comparisons with previous studies (Harris et al., 1990). For all area analyses only individuals with a minimum of 20 locations per year were used, giving an mean of 37 and a maximum of 109 positions per animal per year. For annual activity area analysis Batches 2 and 3 were combined because the first year with $>20$ locations was in
2003 for both these batches. We calculated an annual individual population density index, giving a value for each focal rhino by counting the number of arithmetic means of all the annual locations of other rhinos within a certain radius of the arithmetic mean of the annual locations of the focal rhino. The radius used in these index calculations was determined by the mean radius of all the annual activity areas.

We fitted mixed regression models to examine the effects of sex, age (adult or subadult), release batch, and days after release on distance to the release site, and of sex, age, release batch, year and individual population density index on activity area size and core area size using the glmmPQL function in the MASS library of $R$ (R, 2009), with rhino ID as a random effect because of the different sample sizes among the individuals. Distance to release site, activity area size and core area size were log transformed prior to analysis to achieve a normal distribution of these response variables. All significance levels were set at $5 \%$.

\section{Results}

The distance moved by rhinos from release site to relocations increased with release batch and time since release (Table 2). There was also a tendency for subadults to move further than adults, but there was no difference between the sexes (Table 2). The distance between the last annual position and the release site was similar between years for Batches 1 and 2, whereas it increased annually for Batches 3 and 4 (Fig. 1), except in 2006 when the distance decreased for Batch 3, probably because distance was obtained for only one individual in this batch. The longest distances were in Batch 4 (Fig. 1).

The 57 annual activity area sizes of the 24 rhinos with a minimum of 20 annual relocations varied greatly $(17-6,706$ $\mathrm{km}^{2}$; mean $=260 \mathrm{~km}^{2}$; median $=70 \mathrm{~km}^{2}$ ). Core areas were $5-40 \mathrm{~km}^{2}\left(\right.$ mean $=15.8 \mathrm{~km}^{2}$; median $\left.=9.6 \mathrm{~km}^{2}\right)$. The mean radius of the annual activity areas was $9.1 \mathrm{~km}$, giving a mean individual population density index of $7.1 \pm$ SD 3.2 (range 112) for rhinos within annual activity areas. The activity area size decreased with time for all batches (Fig. 2) but when controlling for sex, age, release batch and year, the activity area sizes and core areas decreased with increasing individual population density index of rhinos (Table 3).

TABLE 1 Number of white rhinos $(n=32)$, by sex and age, released in four batches in Moremi Game Reserve from November 2001 to November 2003. Numbers in parentheses $(n=5)$ represent animals that died shortly after release and were thus not included in the analysis.

\begin{tabular}{llllll}
\hline Batch & Release date & Subadult females & Adult females & Subadult males & Adult males \\
\hline 1 & Nov. 2001 \& Jan. 2002 & 1 & 1 & & $3(1)$ \\
2 & Nov. 2002 & 3 & 2 & $4(1)$ & $1(1)$ \\
3 & June 2003 & 2 & $3(2)$ & 3 & \\
4 & Nov. 2003 & 4 & 5 & & \\
\hline
\end{tabular}


TABle 2 The effects of sex, age category (subadult/adult), release batch and number of days after release on log (distance) from the release site to 2,948 relocations of 27 reintroduced rhinos in Moremi Game Reserve in 2001-2006. The rhinos were reintroduced in four consecutive batches during 2001-2003 (Table 1).

\begin{tabular}{lrlrrr}
\hline Explanatory variables $^{*}$ & \multicolumn{1}{l}{$l$} & SE & df & \multicolumn{1}{l}{$t$} & $\mathrm{P}$ \\
\hline Sex & 0.132 & 0.296 & 23 & 0.448 & 0.658 \\
Age & -0.316 & 0.163 & 24 & -1.937 & 0.065 \\
Release batch & 0.142 & 0.067 & 25 & 2.122 & 0.044 \\
Days after release & 0.000 & 0.000 & 2,920 & 8.098 & 0.000
\end{tabular}

*The generalized linear mixed models with Rhino ID as a random effect were run repeatedly after successively excluding the least significant term until the models included only significant terms

Of the 27 rhinos, 21 stayed within Moremi. Only six left the Reserve and these were all females released in the last batch in November 2003. Two of the females stayed in the Reserve for 1 year near the release site and then moved out in December 2004 to establish themselves at Makgadikgadi Nxai Pan National Park c. $250 \mathrm{~km}$ to the south-east of Moremi, where they still reside. The other four females that left moved out of the Reserve 1 month after their release and were subsequently observed in an area south-west of Moremi, c. $200 \mathrm{~km}$ from the release site. In most cases, they have been sighted together.

\section{Discussion}

In areas where movements are unconstrained rhinos seem to have a self-imposed limit to how far they travel (Linklater \& Swaisgood, 2008) and this may explain why rhinos in the first three batches established themselves at similar distances and not far from the release site. When the last batch of nine animals was released, 18 previously released rhinos were established close to the release site. This situation may have reduced the last batch's chances of establishment within the release area and consequently they dispersed. However, the density of rhinos was low compared to post-release black rhino densities (Linklater \& Swaisgood, 2008).

One reason for the dispersal could be social interactions; four of the animals in Batch 4 were subadult females and
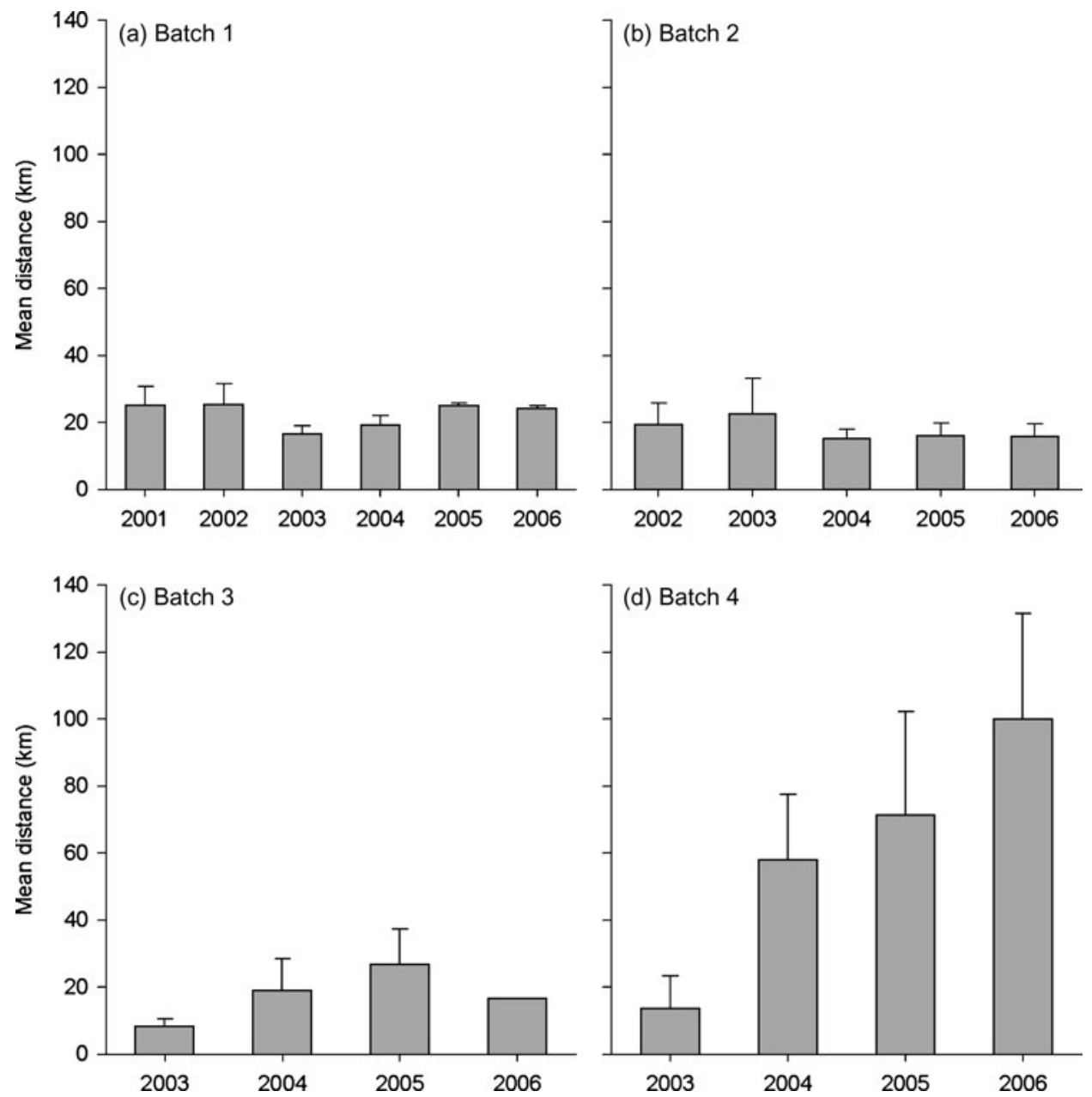

FIG. 1 Mean distance (with SE) from the release point to the annual relocations of 27 rhinos in 2001-2006 that were reintroduced in four batches in Moremi Game Reserve in 2001-2003 (Table 1). 

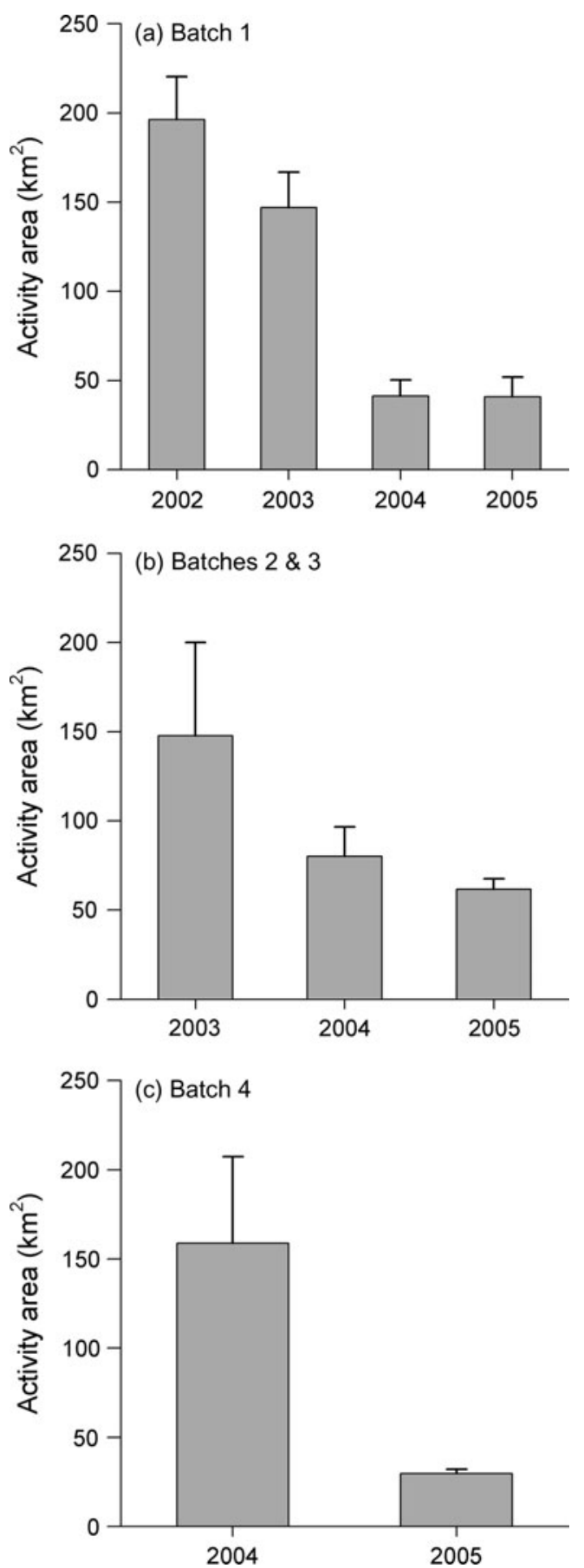

FIG. 2 Mean annual activity area sizes (with SE) for 2002-2005 for 24 white rhinos (for three individuals the number of annual relocations was $<20$ ) reintroduced in four batches (Table 1 ) in Moremi Game Reserve in 2001-2003.

they all left the Reserve. Immature black rhinos have lower survival rates after translocation (Brett, 1998) and subadult females range more widely than adults (Adcock et al., 1998). A high number of adult rhinos already established close to the release site, combined with high social vulnerability, might have triggered dispersal of the subadult females in Batch 4. Our model supports this hypothesis in that there
TABLE 3 The effects of sex, age category (subadult/adult), release batch, year and an individual population density index (see text for further details) on $57 \log$ activity area sizes $\left(\mathrm{km}^{2}\right)$ and $57 \log$ core area sizes $\left(\mathrm{km}^{2}\right.$; see text for further details) of 24 reintroduced rhinos in Moremi Game Reserve in 2002-2005. The rhinos were reintroduced in four consecutive batches during 2001-2003 (Table 1).

\begin{tabular}{|c|c|c|c|c|c|}
\hline Explanatory variables $^{1}$ & $\beta$ & SE & $\mathrm{df}$ & $t$ & $\mathrm{P}$ \\
\hline \multicolumn{6}{|l|}{$\begin{array}{l}\text { Activity area }(95 \% \\
\left.\mathrm{MCP}^{2}\right)\end{array}$} \\
\hline Sex & -0.000 & 0.184 & 20 & -0.000 & 0.999 \\
\hline Age & 0.090 & 0.127 & 21 & 0.707 & 0.488 \\
\hline Release batch & 0.090 & 0.055 & 22 & 1.642 & 0.115 \\
\hline Year & -0.125 & 0.060 & 31 & -2.108 & 0.043 \\
\hline $\begin{array}{l}\text { Individual population } \\
\text { density index }\end{array}$ & -0.072 & 0.017 & 31 & -4.162 & 0.000 \\
\hline \multicolumn{6}{|l|}{ Core area $\left(50 \% \mathrm{MCP}^{2}\right)$} \\
\hline Sex & 0.172 & 0.101 & 22 & 1.709 & 0.101 \\
\hline Age & 0.076 & 0.167 & 21 & 0.457 & 0.652 \\
\hline Release batch & 0.001 & 0.058 & 20 & 0.019 & 0.985 \\
\hline Year & -0.082 & 0.054 & 31 & -1.535 & 0.135 \\
\hline $\begin{array}{l}\text { Individual population } \\
\text { density index }\end{array}$ & -0.044 & 0.016 & 32 & -2.755 & 0.010 \\
\hline
\end{tabular}

${ }^{1}$ The generalized linear mixed models with Rhino ID as a random effect were run repeatedly after successively excluding the least significant term until the models included only significant terms

${ }^{2} \mathrm{MCP}$, minimum convex polygon

was a tendency for subadults to move further when controlling for release batch and time since release.

Another reason could be that the animals rejected the habitat near the release site and subsequently moved long distances in search for better habitat, as seen in other animal reintroductions (Stamps \& Swaisgood, 2007). This is less likely because Moremi Game Reserve previously held a rhino population (extirpated by hunting) and thus the habitat should be suitable for rhinos. Difference in seasons of release could also potentially contribute to differences in dispersal but Batches 2 and 4, with different movement patterns, were both released in November, and Batch 3 was released in June.

It is thus difficult to explain why the four subadult and two of five adult females in Batch 4 dispersed so far beyond the Reserve but several studies have reported similar extensive movements among relocated white rhinos (Booth \& Coetzee, 1988). One possible reason could be that the dispersing animals encountered unsuitable habitat and continued their travel until satisfactory habitat was found. This could be the reason for the long distance travelled by the two individuals that moved $250 \mathrm{~km}$ into the relatively dry Makgadikgadi Nxai Pan National Park to the south of the Reserve. The other four rhinos that dispersed seem to be moving within a relatively large area outside the Reserve and do not seem to be established in a specific area. These animals might have been able to move such a long distance, 
compared to earlier batches, because the flood in 2003 was below average, leaving few obstacles of open water for their dispersal.

The annual activity area sizes for the rhinos in this study were large in the first year after release but comparable in later years to other studies (Kruger National Park, home ranges of 5.5-45.2 km², Pienaar et al., 1993; Murchison Falls National Park, Uganda, home ranges of $6-97 \mathrm{~km}^{2}$, van Gyseghem, 1984). Relocated black rhinos can take up to 3 years to settle down and establish home ranges (Adcock et al., 1998). Prolonged settling time, with gradually reduced exploratory movements and increased familiarity with the habitat and social context, might also have occurred in our study. Familiarity can be an important determinant of range use patterns (Stamps \& Swaisgood, 2007). The animals in Batch 4 moved far away from the release site but the activity area sizes of the individuals remaining in the Reserve were of comparable sizes to the other batches the second year after release.

However, when controlling for sex, age and release batch, both the activity and core area sizes were inversely density dependent. Similarly, Rachlow et al. (1999) found that white rhino females in low-density groups used larger home ranges than females in high-density groups, even if the habitats were similar in the two areas. There is also a tendency for home ranges of female white rhinos to decrease with increasing population density (Pienaar et al., 1993; White et al., 2007). This may indicate territorial behaviour among white rhinos or avoidance of unfamiliar conspecifics. Following a release in a new area black rhinos in large reserves appear actively to avoid other rhinos, minimizing conspecific encounters and subsequent conflicts (Linklater \& Swaisgood, 2008). Avoidance of unfamiliar conspecifics of both formerly and newly released animals might have been the reason for the decrease in the size of the activity areas in Moremi. Inverse density-dependent range use, which may be attributed to interactions among individuals restricting each other's movement at higher densities, has been seen in ungulates and carnivores (Lopez et al., 2005; Dahle et al., 2006).

We have shown that dispersal outside protected areas is likely even when rhinos are released in large reserves such as Moremi. We believe that two reasons may explain the higher proportion of dispersals in the last batch of rhinos released. Firstly, the number of established and establishing animals had reached a threshold at which there was insufficient space for newly released animals to avoid unfamiliar conspecifics and, secondly, the batch had a high proportion of subadult females. To minimize the risk of rhinos leaving an area after release we believe that individuals should be released at different sites, with suitable habitat, to avoid conflicts with any formerly released animals (Lent \& Fike, 2003; Linklater et al., 2006; Linklater \& Swaisgood, 2008). This could be achieved with free releases, i.e. individual rhinos are transported to, and released immediately at, their own separate release site, which is a less expensive method than boma releases and is also recommended by other authors (Linklater et al., 2006). Because activity area sizes of rhinos are inversely density dependent, changing the location of subsequent release sites is also likely to reduce the time before reaching an optimal spatial distribution of rhinos in a given area and, from a management perspective, could be used to maximize the rhino population of an area.

\section{Acknowledgements}

We are grateful to the Department of Wildlife and National Parks (DWNP) and Okavango Wilderness Safaris (OWS) for permission to use the rhino monitoring data. We would like to thank the Anti-Poaching Unit of DWNP and OWS rhino reintroduction project personnel, Nick Galpine, Map Ives and Phoasta Mpho Malongwa for their extensive monitoring of the rhinos since the project's inception. Maun Research personnel, and particularly Eda Gaobinelwe, helped us whenever we asked. Pelotshweu Pearl Galebotswe and Mercy Monyadzwe assisted during fieldwork. Connie Masalila, Masego Dhliwayo, Inmaculada Gomez Jimenez and Samuel Mosweu assisted with geographic information system data.

\section{References}

Adcock, K., Hansen, H.B. \& Lindemann, H. (1998) Lessons from the introduced black rhino population in Pilanesberg National Park. Pachyderm, 26, 40-51.

Beehner, J.C., Bergman, J.J., Cheney, D.L., Seyfarth, R.M. \& Whitten, D.L. (2005) The effect of new alpha males on female stress in free-ranging baboons. Animal Behaviour, 69, 1211-1221.

Bоотн, V.R. \& Coetzee, A.M. (1988) The capture and relocation of black and white rhinoceros in Zimbabwe. In Translocation of Wild Animals (eds L. Nielsen \& R.D. Brown), pp. 191-209. Wisconsin Humane Society, Milwaukee, USA.

Bowen-Jones, E. \& Entwistle, A. (2002) Identifying appropriate flagship species: the importance of culture and local contexts. Oryx, 36, 189-195.

B Ret T, R.A. (1990) The black rhino sanctuaries of Kenya. Pachyderm, $13,31-34$.

BRETT, R.A. (1998) Mortality factors and breeding performance of translocated black rhinos in Kenya: 1984-1995. Pachyderm, 26, $69-82$.

Dahle, B., Støen, O.-G. \& Swenson, J.E. (2006) Factors influencing home-range size in subadult brown bears. Journal of Mammalogy, 87, 859-865.

Dangerfield, J.M. \& Schuurman, G. (2000) Foraging by fungus growing termites in the Okavango Delta, Botswana. Journal of Tropical Ecology, 16, 717-731.

Department of Wildlife and National Parks (2005) Botswana Rhino Management Strategy. Department of Wildlife and National Parks, Gaborone, Botswana. 
Dublin, H.T. \& Wilson, A. (1998) The Fight for Survival: Four Decades of Conserving Africa's Rhinos. WWF International, Gland, Switzerland.

Emslie, R. \& Brooks, M. (1999) African Rhino: Status Survey and Conservation Action Plan. IUCN, Gland, Switzerland.

Harris, S., Cresswell, W.J., Forde, P.G., Trewhella, W.J., Woolard, T. \& Wray, S. (1990) Home-range analysis using radio-tracking data-a review of problems and techniques particularly as applied to the study of mammals. Mammal Review, $20,97-123$.

Hillman-Smith, A.K.K., Owen-Smith, N., Anderson, J.L., Hall-Martin, A.J. \& Selaladi, J.P. (1986) Age estimation of the white rhinoceros (Ceratotherium simum). Journal of Zoology, 210, 355-379.

Hitchins, P.M., Keep, M. \& Rochat, K. (1972) The capture of black rhinoceros in Hluhluwe Game Reserve and their translocation to the Kruger National Park. Lammergeyer, 17, 18-30.

Hofmeyr, J., Ebedes, H., Fryer, R. \& De Bruine, J. (1975) The capture and translocation of the black rhinoceros Diceros bicornis Linn. in South West Africa. Madoqua, 9, 35-44.

IUCN (2008) 2008 IUCN Red List of Threatened Species. IUCN, Gland, Switzerland. Http://www.iucnredlist.org [accessed 17 August 2009].

Kenward, R.E., South, A.B. \& Walls, S.S. (2003) Ranges 6 Manual. Anatrack Ltd, Wareham, UK.

Lent, P.C. \& FiKe, B. (2003) Home ranges, movements and spatial relationships in an expanding population of black rhinoceros in the Great Fish River Reserve, South Africa. South African Journal of Wildlife Research, 33, 109-118.

Linklater, W., Flammand, J., Rochet, Q., Zekela, N., Macdonald, E., Swaisgood, R. et al. (2006) Preliminary analyses of the free-release and scent-broadcasting strategies for black rhinoceros re-introduction. Ecological Journal, 7, 26-34.

Linklater, W. \& Swaisgood, R. (2008) Reserve size, release density and translocation success: black rhinoceros movements, association, injury and death after release. Journal of Wildlife Management, 72, 1059-1068.

Lopez, R.R., Harveson, P.M., Peterson, M.N., Silvy, N.J. \& FRANK, A.P. (2005) From the field: changes in ranges of Florida Key deer-does population density matter? Wildlife Society Bulletin, 33, 343-348.
Mosillo, M., Heske, E.J. \& Thompson, J.D. (1999) Survival and movements of translocated raccoons in north central Illinois. Journal of Wildlife Management, 63, 278-286.

Pienaar, D.J., Du Bothma, P.J. \& Theron, K.G. (1993) White rhinoceros range size in the south western Kruger National Park. Journal of Zoology, 229, 641-649.

R (2009) The R Project for Statistical Computing. Http://www. r-project.org/ [accessed 29 June 2009].

Rachlow, J.L., Kie, J.G. \& Berger, J. (1999) Territoriality and spatial patterns of white rhinoceros in Matobo National Park, Zimbabwe. African Journal of Ecology, 37, 295-304.

Reinert, H.K. \& RUPERT, R.R. (1999) Impacts of translocation on behaviour and survival of timber rattlesnakes, Crotalus horridus. Journal of Herpetology, 33, 45-61.

Rogers, L.L. (1988) Homing tendencies of large mammals. A review. In Translocation of Wild Animals (eds L. Nielsen \& R. Brown), pp. 76-92. Wisconsin Humane Society, Milwaukee, USA.

Stamps, J. \& Swaisgood, R. (2007) Some place like home: experience, habitat selection and conservation biology. Applied Animal Behaviour Science, 102, 392-409.

Tíae, M. (2002) Reintroduction of white rhinos to Moremi Game Reserve. Pachyderm, 32, 87.

VAn Gyseghem, R. (1984) Observations on ecology and behaviour of the northern white rhinoceros (Ceratotherium simum cottoni). Zeitschrift fuer saugetirkunde, 49, 348-358.

White, A.M., Swaisgood, R.R. \& Czekala, N. (2007) Ranging patterns in white rhinoceros, Ceratotherium simum simum: implications for mating strategies. Animal Behaviour, 74, 349-356.

\section{Biographical sketches}

Ole-Gunnar $S_{\text {tøen }}$ is a wildlife ecologist with particular interests in wildlife management and large carnivore ecology. He has research and field experience in Europe, Africa, Asia and America. MO M P OLO K I Lettie Pitlagano is a wildlife ecologist with a particular interest in conservation and wildlife management. S TEIN R. MOE is a wildlife ecologist with particular interests in wildlife management and plantanimal interactions in the tropics. He has been involved in research projects in several African and Asian countries. 